\title{
ARQUITECTURA BARROCA DE LOS CARMELITAS EN SANLÚCAR DE BARRAMEDA.
}

\author{
FERnANdo Cruz Isidoro \\ UNIVERSIDAD DE SEVILLA
}

\section{RESUMEN}

Se estudia, a través de la documentación original que se aporta, consultada en el Archivo Ducal de Medina Sidonia, la fundación por el IX duque don Gaspar Alonso Pérez de Guzmán, en 1641, de los conventos masculinos carmelitas, calzados y descalzos, de Sanlúcar de Barrameda (Cádiz); la historia constructiva de los varios edificios por los que pasaron y levantaron hasta llegar a los definitivos; y el devenir histórico de ambos inmuebles hasta su desamortización en 1835, que provocó la pérdida del convento de los calzados y la transformación del otro en la actual parroquia del Carmen.

Palabras Clave: Arquitectura barroca; Orden Carmelita; Sanlúcar de Barrameda; mecenazgo artístico; Casa de los Guzmanes; patronazgo; Gaspar Alonso Pérez de Guzman; Archivo Ducal de Medina Sidonia.

\section{ABSTRACT}

This article studies, for the original documentations consulted in Medina Sidonia's archive, the foundation for Don Gaspar Alonso Pérez de Guzmán, $9^{\text {th }}$ duke, in 1641, of the footwear and discalced Carmelite masculine convents in Sanlúcar de Barrameda (Cádiz); the construction of the different buildings that they erected, and the history of them until the redemption in 1835 , with the disappearance of one and the transformation in parochial church of discalced.

Key words: Baroque architecture; Carmelite Order; Sanlúcar de Barrameda; Artistic patronage; Guzmanes's House; patronazgo; Gaspar Alonso Pérez de Guzmán; Ducal File of Medina Sidonia.

La Orden carmelitana masculina en sus dos ramas, calzada y descalza, con gran tradición en la provincia de Andalucía, tuvo una primera intentona de fundar conventos en Sanlúcar de 
Barrameda en la primavera de 1640, pero el Cabildo municipal se opuso abiertamente, quizás influido por otras religiones asentadas en la ciudad, que veían peligrar limosnas y privilegios. El acta capitular de 30 de junio recoge la petición elevada a don Gaspar Alonso Pérez de Guzmán, IX duque de Medina Sidonia y señor de Sanlúcar, para que no les concediera su licencia, una firme decisión que se ratificó un año más tarde, en la reunión del cabildo de 15 de julio de 1641. Sin embargo, el duque ignoró el ruego, porque estaba resuelto a fundar sendos conventos, ya que era gran devoto de Santa Teresa de Jesús, como lo había sido su esposa doña Ana María de Guzmán y Aragón, fallecida en 1637.

\section{LOS CONVENTOS DEL CARMEN CALZADO}

\subsection{De la ermita de San Sebastián al convento del Carmen Viejo (desaparecido)}

Para legalizar la llegada de los frailes calzados, el duque solicitó el beneplácito del arzobispo de Sevilla, cardenal don Gaspar de Borja y Velasco, que concedió el 11 de agosto de 1640, y que tuvo que ordenar con firmeza el 11 de septiembre al vicario sanluqueño Luis de León Garavito que no les impidiese su entrada en la ciudad. Para la fundación, el duque les entregó en un primer momento la ermita extramuros de San Sebastián, de la que tomaron posesión el 9 de julio de 1641, mediante la fórmula de consagración por el vicario de dos Sagradas Formas, una de las cuales se depositó en un tabernáculo en el altar mayor, tras lo cual el provincial carmelita abrió y cerró las puertas de la ermita en señal de dominio. Allí permaneció la comunidad, compuesta por doce individuos (ocho sacerdotes, tres coristas y un lego) sólo un mes, pues los regidores municipales pensaron que con la pérdida de la ermita también se quedaría la ciudad sin el terreno adyacente, que se necesitaba para el pastoreo del ganado forastero, con lo que propiciaron, con la anuencia del duque, que se trasladasen el 9 de agosto a unas casas principales en el Carril Nuevo, actual de los Ángeles "hacia el pie de la cuesta de este nombre". Al año siguiente la comunidad compró otras fincas linderas, extendiéndose "hasta la esquina de la calle de la Alcoba", donde labraron "nueva iglesia más cómoda y amplia" , con puerta a la calle Juan de Dueñas, actual Carmen Viejo². Bajo estricta regla de observancia, su economía, basada en dotaciones de capellanías de misas, donaciones, herencias de religiosos y limosnas, fue muy pobre, como se refleja en las actas de los carmelitas andaluces de 1653 y 1655 , donde se manifiestan las deudas contraídas por causa de la ampliación, lo mismo que en la petición de 1672 de recibir novicios que atrajesen las limosnas de familiares, lo que era contrario a la estricta observancia. Según los estatutos fechados en San Juan del Puerto, en marzo de 1629, reformados diez años más tarde, tenían prohibido salir fuera de los muros del convento a no ser por causa grave, permanecer en sus celdas, y guardar en lo posible el silencio ${ }^{3}$.

En el edificio, del que aparentemente no se conserva nada en el actual caserío, perseveraron menos de 60 años, pues lo abandonaron en 1699 dada su estrechez y mala construcción al haberse levantado en sitio en pendiente por donde corrían las aguas, con la consiguiente humedad insalubre, a lo que había que añadir el sobresalto continuo de los disparos de la artillería del cercano castillo de Santiago, que "les causaba pavor, ruina e interrupción en los divinos oficios".

1 VELÁZQUEZ GAZTELU, Juan Pedro: Fundaciones de todas las iglesias, conventos y ermitas de la Muy Noble y Muy Leal ciudad de Sanlúcar de Barrameda. Año de 1758. Sanlúcar de Barrameda: A.S.E.H.A. 1995. Estudio prelim. y transcripción por Manuel Romero Tallafigo, pp. 452-455. VELASCO BAYÓN, Balbino.: Historia del Carmelo Español. Vol. III Provincias de Castilla y Andalucía 1563-1835. Roma: Institutum Carmelitanum, 1994, pp. 361-362.

2 CLIMENT BUZÓN, Narciso: Calles y plazas de Sanlúcar de Barrameda. Recorrido histórico. Sanlúcar de Barrameda: A.S.E.H.A., 2004, p. 130.

3 VELASCO BAYÓN, Balbino: Historia del Carmelo... ob. cit., pp. 437, 439-442, 444, 446, 449-450, 491. 


\subsection{El convento calzado de la calle Ancha (desaparecido)}

Decididos a trasladarse más a la ribera, a la calle Ancha, adquirieron las casas principales de Felipe Manuel de Ávila Ponce de León y otros solares contiguos, "las cuales fueron secretamente reparando y de repente, una mañana, sin haber impetrado las licencias necesarias, amaneció puesta la campana en las referidas casas, repicándola y abiertas las puertas de un nuevo sagrario". Lindaba el nuevo convento con la Calle de los Moros, actual Castelar, quedando a su espalda la de la Bolsa. Esa actitud taimada molestó al cabildo municipal, que parece tenía destinado el lugar para la Compañía de Jesús, y a las otras dos comunidades asentadas en la zona, mínimos de la Victoria y dominicos de Santo Domingo, que acudieron al Ordinario, al Nuncio y al Consejo de Castilla, ganando el pleito, pues el 12 de marzo de 1700 el corregidor obligó a los carmelitas a volver al Carril Nuevo, aunque por pocos meses, ya que el 18 de mayo, con provisión del 24 , obtuvieron permiso para el traslado, que hicieron en solemnísima procesión ese mismo día de San Juan.

Con el tiempo, la congregación, de unos veinte individuos, labró una pequeña iglesia, calificada por el historiador dieciochesco Velázquez Gaztelu de "baja y estrecha por fuerza, sin cosa digna de notarse en ella más que el altar y primoroso retablo de la nave derecha, dedicado a Ntra. Sra. del Carmen, que les sirve de Sagrario", porque su escasez de medios no les permitió "ni labrar iglesia en forma, ni del proyectado convento más que un ángulo, hacia la calle, hecho a arrempujones y con malísima disposición"4.

Sin embargo, para 1835, cuando la comunidad fue exclaustrada y el inmueble desamortizado, el conjunto conventual era bastante amplio. Cercado por las calles Ancha, Castelar y Bolsa, lindaba para entonces con casas de Carlos Filippo y de Francisco Martínez, ocupando casi por completo la manzana. Como es habitual en esta tipología religiosa urbana, la vida comunitaria era bastante autónoma, lo que implicaba salas "especializadas". El edificio, de doble planta, contaba con once celdas altas y otras tres bajas para el retiro nocturno, además de una sala $D e$ profundis, un refectorio para la comida en común, un amplio corral y, por supuesto, la iglesia, "dentro del mismo convento". Era de planta basilical de tres naves, posiblemente de cuatro tramos, pues aparte del retablo mayor columnario de tres calles de madera sin dorar, con las imágenes de la Inmaculada y los santos carmelitas Alberto de Sicilia y Ángelo, disponía de un retablo-Sagrario en la cabecera de la nave del evangelio, de la hermandad del Carmen, donde se rendía culto a su titular, a un San José con el Niño, y a San Pascual Bailón, y de otros siete altares a lo largo de las naves colaterales: el de la hermandad de las Angustias, el de San Antonio portando al Niño en brazos, el de un Crucificado, el del Ángel de la Guarda, el de San José con el Niño, el de Ntra. Sra. de los Dolores y uno sin imagen alguna ${ }^{5}$. El coro se hallaba en alto para la asistencia privada de los frailes, cargando sobre un sotocoro que servía de vestíbulo abierto a la ciudad. Su espadaña-campanario tenía dos campanas, una grande y otra chica, mientras que una tercera se encontraba en el refectorio para llamar a la comida ${ }^{6}$.

El lugar exacto de estos espacios no se ha localizado, al no conservarse restos visibles ni arqueológicos que sepamos, ni el historiador Fernando Guillamas, que los conoció tras su desamortización, explicitar nada en 1858 cuando escribe, tan solamente, que estaba "en la calle

$4 \quad$ VELÁZQUEZ GAZTELU, Juan Pedro: Fundaciones de todas las iglesias... ob. cit., pp. 455-459. En 1752 el convento poseía cuatro casas, una bodega, 40 censos y unas rentas de 5.725 reales, soportando gravámenes de 1.480 reales. SANLÚCAR DE BARRAMEDA. 1752. SEGÚN LAS REPUESTAS GENERALES DEL CATASTRO DE ENSENADA. 1752. Introducción Jesús Campos Delgado y Concepción Camarero Bullón. Madrid: Tabapress, 1995, pp. 141, 173.

Archivo Ducal de Medina Sidonia (en adelante A.D.M.S.) leg. 1.646.

A.D.M.S. leg. 1.646 
Ancha y en él se ha hecho el teatro" ", al parecer en el n ${ }^{\circ} 13$ de una vía que se había rotulado Ancha del Carmen Calzado ${ }^{8}$. En su lugar se levantaron varias casas particulares, el huerto se sumó a otras adyacentes, y en lo que quedó de su amplio terrero, que daba a Castelar, se construyó en 1842 el Teatro Principal, un histórico edificio que ha sido derribado recientemente para levantar un centro comercial y un bloque de viviendas, excavando varios metros de profundidad para la cimentación y garajes, arrasando cualquier vestigio que quedase en el subsuelo?.

\section{LOS CONVENTOS DEL CARMEN DESCALZO.}

\subsection{La primitiva fundación en la ermita de San Roque, advocada de Ntra. Sra. del Carmen (desaparecida).}

Los carmelitas descalzos llegaron a la ciudad a la par que la original rama descalza, en 1641, igualmente invitados por el duque don Gaspar. Representaban la reforma masculina de la regla, auspiciada por Santa Teresa con la ayuda de San Juan de la Cruz, para volver a la primitiva austeridad del Carmelo, con el beneplácito del papa Pío V y la confirmación de Gregorio XIII en 1580.

La venta de las joyas de la primera esposa del duque, doña Ana María de Guzmán y Aragón, gran devota de la santa de Ávila, sirvió para dotar la fundación de este convento y del femenino, a los que asignó 11.000 ducados. Don Gaspar estableció concierto el 11 de noviembre de 1640 con el padre provincial de Andalucía fray Luís de San Jerónimo, ante el escribano Luís Díaz Palomino, para fundar convento con capacidad para veinticuatro frailes, labrarlo a su costa, y dotar su manutención con 300 ducados y 100 fanegas de trigo anuales, empleando su hacienda cuando su situación precaria lo permitiese, e igualmente se comprometía a fundar, en un futuro, convento para la rama femenina descalza. Previamente el Definitorio general carmelita lo había aprobado el día 7 en el convento madrileño de San Hermenegildo ${ }^{10}$, y concedido al duque el patronato de las provincias de carmelitas descalzos de Andalucía y de las Indias, que se mantendría hasta $1740^{11}$.

De inmediato se iniciaron los trámites ante el arzobispo de Sevilla don Gaspar de Borja, que dio licencia el $1^{\circ}$ de marzo de 1641, por mano del procurador general Francisco del Carpio. El duque les entregó la desaparecida ermita de San Roque, que se levantaba en la calle del Chorrillo, la actual Ganado en su parte baja, así llamada por discurrir un remanente de aguas que bajaba desde la Fuente Vieja hacia Madre de Dios, de la que la comunidad tomó posesión el 18 en presencia del licenciado Luís de León Garavito, vicario de la ciudad, y del presbítero licenciado Matías de Marcilla, notario apostólico y público, dándole el nombre de Ntra. Sra. del Carmen, "por dezir aver señalado la dicha iglesia el exmo. Sr. duque de Medina en el interim que se señalase otro sitio donde se funde el dicho convento". Los carmelitas que estuvieron presentes fueron fray Luís de Jesús y María, rector del Colegio del Santo Ángel de la Guarda de Sevilla, y los padres fray Francisco de la Cruz, que quedó como primer prior, y fray Miguel de San Juan ${ }^{12}$.

\footnotetext{
GUILLAMAS Y GALIANO, Fernando: Historia de Sanlúcar de Barrameda. Madrid: Imprenta del Colegio de sordomudos y de ciegos, 1858. Reprod. facs. Sanlúcar de Barrameda: A.S.E.H.A, 1990, p. 113.

CLIMENT BUZÓN, Narciso: Calles y plazas de Sanlúcar... ob. cit., pp., 39, 152-153.

9 VELASCO BAYÓN, Balbino: Historia del Carmelo... ob. cit., pp. 571, 577, 586, 590. BARBADILLO DELGADO, Pedro: Historia de la ciudad de Sanlúcar de Barrameda. Cádiz, 1942. Reprod. facs. Sanlúcar de Barrameda: Ayuntamiento, 1989 , p. 368

10 A.D.M.S. leg. 5.703.

11 VELÁZQUEZ GAZTELU, Juan Pedro: Fundaciones de todas las iglesias... ob. cit., pp. 451-465.

12 A.D.M.S. leg. 1.091
} 
Con el traslado definitivo de don Gaspar a Valladolid, la perdida del señorío sanluqueño y la Casa acosada por acreedores, el concierto quedó roto y los carmelitas tuvieron que conformarse con tan corto lugar, ampliado con algunas casas colindantes y traseras a la ermita, entre las calles del Chorrillo y del Rastro, "hasta la de la Tenería", que recibía el nombre por las casas de matanza que había junto a la vieja carnicería, y por donde discurría el arroyo de los Abades, que atravesaba el matadero y servía como desagüe de sus desperdicios, molestando a los religiosos, "además de la fetidez, estar en sitio tan angosto y cercado de estorbos públicos". La ampliación fue posible gracias a la donación, en 1645, de unas casas por María Rodríguez, difunta para enero de 1646, que sirvieron para dotar una capellanía de misas, con un principal de 1.100 reales, que rentaban 24 ducados al año "para sitio de aquella nueva fundación", que fue aprobada por el General de la Orden, fray Juan Bautista, el 18 de ese mes, en el convento madrileño ${ }^{13}$. Se solicitó al ayuntamiento poder cerrar por la anchura de su convento la calle del Rastro y la falda del cerro de la Huerta Grande, para extenderse por esa zona, lo que fue concedido en cabildo de 10 de diciembre de 1647, tras el informe del Maestro mayor de la ciudad, el alférez Martín Rodríguez de Castro, que lo había sido durante años de las obras ducales. Posiblemente el arquitecto, tracista y constructor del convento de Capu$\operatorname{chinos}^{14}$, fue quién acondicionó la ermita por orden de don Gaspar, y sería elegido para la reforma y construcción del nuevo convento, porque dos años más tarde emitió un nuevo informe, que se leyó en la reunión del 15 de junio de 1649, que acordó el permiso para abrir la calle y hacer la necesaria alcantarilla que canalizase las aguas.

Como ocurre con la arquitectura carmelitana, el diseño del edificio y de su ampliación se llevó a cabo por un miembro de la orden, un padre o lego arquitecto que desde Madrid, desplazándose a donde fuese preciso, efectuaba las trazas, que siguen unas normas básicas, acomodadas al severo espíritu de la reforma, aunque adaptándose a las necesidades del lugar. Se conserva su plano, reproducido unos años después por pérdida del original, en el Archivo Ducal de Medina Sidonia, formando parte de un pleito que la comunidad mantuvo en 1806. Se levantó en dos hojas, una de 35,5 cms. de ancho por 50,1 de alto, y otra de 34 x 54,5, en tinta marrón y almagra, rubricado por fray Juan de San Miguel en Sanlúcar el 29 de julio de $1660^{15}$. (Lám. 1)

Sin embargo, el descontento de los frailes por el lugar se percibe en el tenor del permiso que consiguieron del Definitorio el 16 de mayo de 1653: "atento a no tener competente iglesia ni claustro, para que mientras no tubiere alguna de las dos cosas acabada, pudieran las procesiones salir por una puerta de la iglesia y entrar por otra", lo que demuestra serias deficiencias, pues se vulneraba la clausura ${ }^{16}$. Éstas y otras circunstancias animaron en 1657 el trasladarse unos metros más allá y fundar nuevo convento en el sitio alto de la Huerta Grande, lo que el Ayuntamiento denegó rotundamente por no contar con las preceptivas licencias del monarca ni del arzobispado hispalense, y por ser lugar público usado como recreo por el vecindario, amén de otros perjuicios que se podrían crear, como los que hizo ver el duque de Medinaceli, por entonces Capitán General del Mar Océano y de todos sus puertos, en el Real Consejo de Castilla, que alegó podía convertirse en una plaza fuerte que batiría la ciudad si caía en manos enemigas, ganando un despacho del Real Consejo de Guerra por el que se prohibía tajantemente su construcción. Un nuevo intento se paralizó en 1659, por lo que la comunidad decidió buscar lugar menos problemático y llevar el asunto con absoluto sigilo.

13 A.D.M.S. leg. 1.091; leg. 1.646.

14 Sobre este arquitecto véase: CRUZ ISIDORO, Fernando: El convento sanluqueño de Capuchinos. Arte e Historia de una Fundación Guzmana. Sanlúcar de Barrameda: A.S.E.H.A., 2002, pp. 46-51. Del mismo autor: "La Casa ducal de Medina Sidonia y el convento de capuchinos de Sanlúcar de Barrameda: patronato y construcción”. Laboratorio de Arte $^{\circ}$ 13, (2000), pp. 79-101.

15 A.D.M.S. leg. 1.009

16 A.D.M.S. leg. 1.091. 

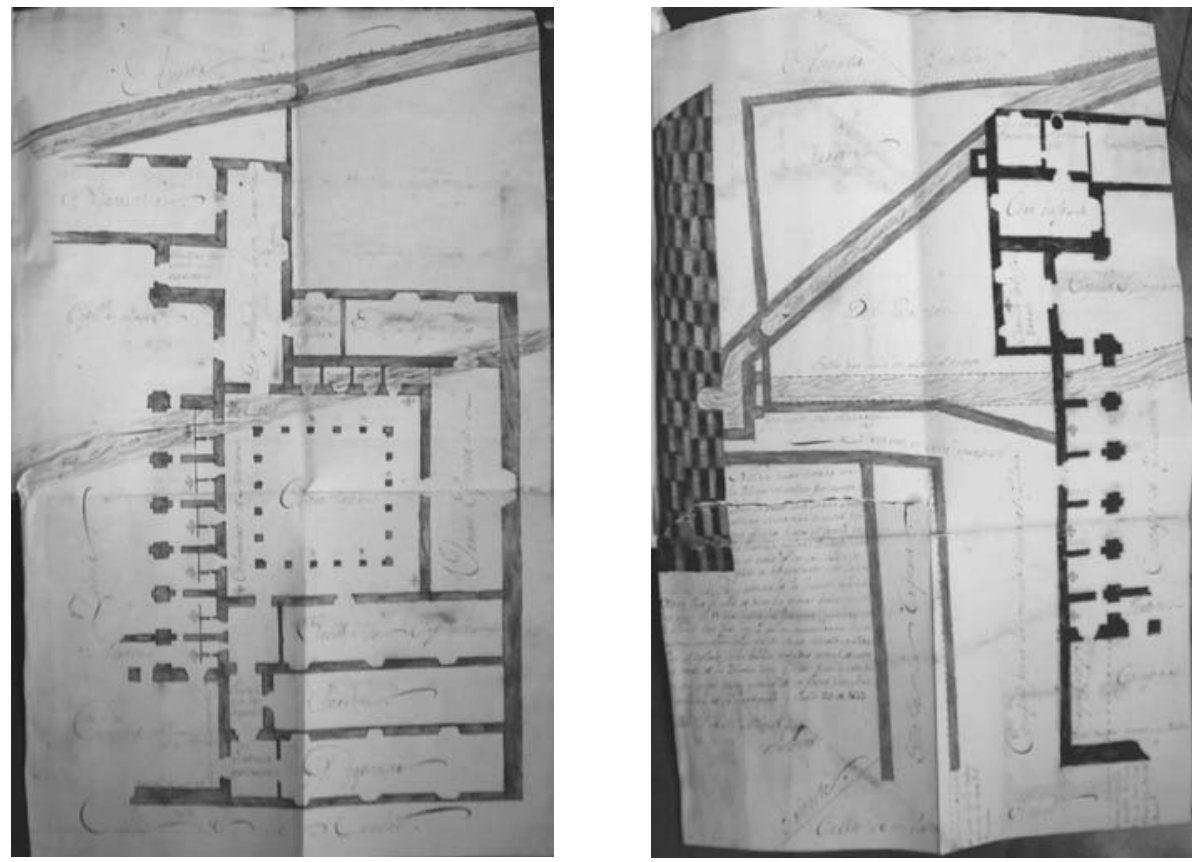

Láms. 1 a y b. Planos del convento del Carmen descalzo de la calle Ganado (sobre la antigua ermita de San Roque). 1660. A.D.M.S. leg. 1.009.

\subsection{La definitiva fundación del Carmen descalzo en la calle San Juan (actual parroquia del Carmen).}

Como la comunidad no podía "perseverar en el sitio y lugar que ahora tiene, por las muchas descomodidades que en él se han experimentado", el Vicario general de los carmelitas, fray Gabriel de la Madre de Dios, concedió permiso el 31 de enero de 1661 para trasladarse al "sitio que llaman el Corral de Alberto", con la condición de levantar "primero la parte que ha de servir de iglesia con decencia suficiente para el Santísimo Sacramento, y para decir las horas canónicas, y dispuesta habitación de lo que ha de ser convento con clausura competente”. Se escogió ese sitio por ser "el mejor de toda la ciudad", y además "se podía comprar con comodidad, respecto de valer muy poco (...), por averse desaveçindado de ella lo más de la gente de trato y comercio”. El ajuste lo llevó el padre provincial, fray Antonio de Jesús María, con Juan Carrero, administrador de la finca en nombre de su dueña, María de San Josef, viuda de Diego de la Peña, y consistía en unas casas con corral en la calle del Baño. En las condiciones la señora cedía los tributos que pagaban las posesiones circunvecinas, y los frailes se comprometieron a hacer frente a las cargas que tenía y a pagarle 1.500 ducados. La toma de propiedad y el traslado se efectuó el 22 de febrero.

La Ciudad mantuvo una postura de complacencia, pero se opusieron los frailes mínimos, que interpusieron pleito en el arzobispado "por causa de la cercanía del sitio", que aunque ganaron los carmelitas, llevaron hasta el Consejo de Castilla, que les dio la razón. Entretanto hubo un pacto incumplido, pues el 19 de marzo el provincial carmelita fray Antonio de Jesús María escribió que había conseguido que retirasen su férrea oposición a cambio de "que el 
dicho nuestro convento, en tiempo ninguno, ahora ni para siempre jamás, ponga la puerta de la iglesia a la calle que llaman de San Juan de la dicha ciudad" 17.

Con esa provisión los carmelitas se vieron obligados a regresar temporalmente a su antiguo convento de San Roque, donde permanecieron ocho meses en precarias condiciones, hasta que salieron victoriosos en ese mismo tribunal, al obtener Real Cédula favorable, firmada por Felipe IV, el 24 de abril de 1662. El documento recoge las razones expuestas por uno y otro contendiente, totalmente contrapuestas. Los carmelitas alegaron haber estado más de veinte años sufriendo una gran incomodidad, por ser "el sitio muy enfermo y pasar por él un arroyo que llevaba todas las inmundicias que salían de dicha ciudad, con que continuamente los dichos religiosos estaban enfermos, como por el registro grande que había, faltándose a la clausura y recoleción que se observaba en dicha religión", por lo que "les havía sido fuerça buscar nuevo sitio, comprando casas en la calle del Baño, donde se havían marchado sin haçer agravio a nadie ni causar perjuicio aluno, sino antes con beneplácito de toda la ciudad y vezinos de ella, por el beneficio que se les seguía de la asistencia del dicho combento". Terminan afirmando haber cumplido la legalidad, y haber guardado la preceptiva distancia con otras fundaciones y, sin embargo, remarcan como los mínimos, "con siniestra relación”, habían ganado provisión mayor del Consejo de Castilla, que le impelió el abandonar su casa y demoler lo construido, lo que hicieron mansamente, antes de que se les notificase de forma oficial. Cargan las pésimas condiciones de vida que habían tenido que soportar en los meses siguientes, pues "el dicho combento estaba al presente sin puertas ni ventanas, derribados los tabiques y sin tener abrigo ninguno los religiosos ni comodidad para poder tener los enfermos, demás de la falta de clausura respecto del dicho arroyo y vezinos, que juzgaban y registraban dicho combento y tenían servidumbre para echar inmundicias por el dicho arroyo, que estaba por medio del dicho sitio del combento".

En la provisión el Consejo aprobó su traslado a la calle del Baño, ordenando acatar su decisión al Ayuntamiento y a los frailes de la Victoria, los cuales, por voz de su procurador Francisco Bermejo el $1^{\circ}$ de febrero, lo impugnan, alegando que los carmelitas venían incumpliendo la ley, pues consideraban ilegal su fundación en 1641, y falsas las razones expuestas, "porque la dicha ermita era una iglesia muy capaz y especialmente para religiosos descalços, y la casa y combento tenía lo neçesario para la comunidad de religiosos y para su bibienda y clausura, y tenía las celdas y oficinas y todo lo demás importante. Y porque el arroyo del Chorrillo, de donde les benía incomodidad, no sólo no se le daba, sino que les era muy útil, porque con el agua tenían la suficiente para regar las legumbres y árboles de su huerta, de la qual siempre habían usado para este efecto y por el no iban inmundicias algunas", remarcando que "el dicho arroyo era de agua clara y corriente" y "que el dicho sitio era el más sano de la dicha ciudad"18. A pesar de estas contundentes palabras, el Consejo reafirmó el traslado, ordenando al gobernador de la ciudad y al ayuntamiento acatasen su decisión, efectuándose a finales de año un solemne traslado del Santísimo "en procesional pompa, a que asistieron clero, Ciudad, sagradas religiones, y todo lo noble y lucido de este pueblo". En esas casas permanecerían de manera precaria algunos años, con una reducida iglesia y convento, hasta que compraron las viviendas colindantes, y se hicieron con toda la manzana, que quedó rodeada por las calles de San Juan, del Chorrillo y del Baño, y por un callejón, actual pasaje de las Angustias, "a donde cae una de las puertas de la iglesia, que por ser propia de los padres, le cierran de noche sus dos puertas de los extremos" 19 .

El solar adquirido fue tan amplio que los carmelitas pudieron, en palabras de Velázquez Gaztelu, "labrar uno de los mayores conventos de su religión", obra en la que se empeñaron por décadas, y que lograron llevar a término gracias a las limosnas y fondos que acumularon de diversas maneras. (Lám. 2)

\footnotetext{
A.D.M.S. leg. 1.091

A.D.M.S. leg. 1.091.

VELÁZQUEZ GAZTELU, Juan Pedro: Fundaciones de todas las iglesias... ob. cit., p. 471.
} 


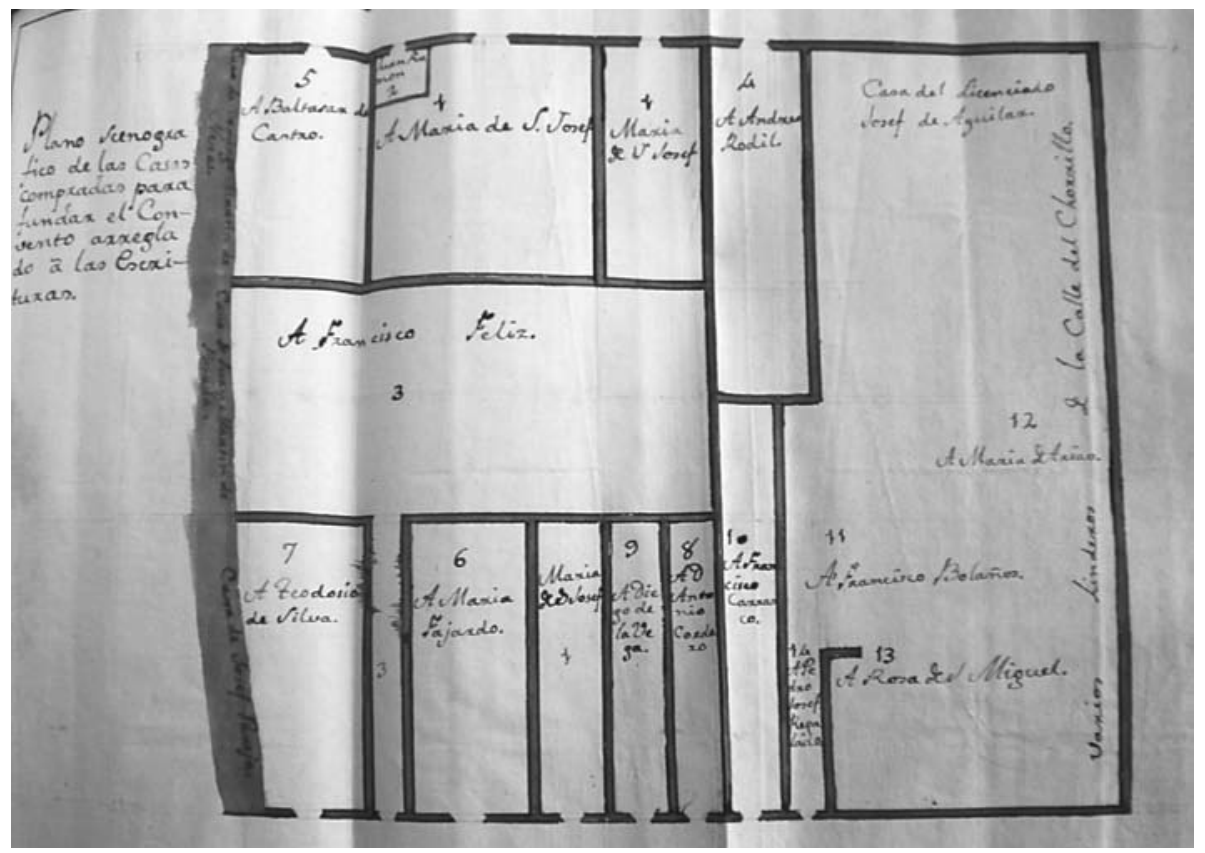

Lám. 2. Plano con el conjunto de solares sobre el que se edificó el convento del Carmen descalzo en la calle San Juan. A.D.M.S. leg. 1.009.

El 10 de julio de 1662, el provincial fray Rodrigo del Santísimo Sacramento, autorizó a su prior, el padre fray Francisco de San Elías, el dar a censo 1.000 ducados, que se tomaron prestados de la dote de la hermana Laureana Agustina de Santa Inés, profesa en las descalzas sanluqueñas, para "comprar más sitio, para perfecta y cumplida capacidad de el convento, un corral de vecindad que esta inmediato al sitio". Se preveía "labrar y perficionar la competente clausura y suficiente habitación para los religiosos" ${ }^{20}$. Al día siguiente, el provincial autorizó otra "delicada" operación monetaria, emplear el depósito de 3.000 pesos, en moneda de plata y vellón y una cadena de oro que se vendió, que el padre fray Juan de Jesús había traído de las Indias, que por su ingenio y palabra había acumulado de limosnas durante el trienio anterior, y que tenía como finalidad la institución de una obra pía. En verdad lo que hizo fue legalizar su uso fraudulento pues con antelación, el prior, la había gastado por entero "en la compra de sitio y fábrica del". Como resultado se inició una investigación, en la que éste declaró haber recibido autorización, a principios de octubre de 1660, del anterior provincial, fray Antonio de Jesús María, para la compra del solar y hacer frente a los gastos de la construcción. Además adujo que esa cantidad estaba destinada por su dueño para comprar la Huerta Grande y que, al no ser posible, lógicamente era "para la fábrica deste dicho convento". Termina señalando que no había más capital del que echar mano, pues la ayuda de las monjas descalzas había sido muy escasa, por cuanto sólo pudieron entregar 70 ducados de la dote de la madre María de Espíritu Santo y una cadena de oro de la madre Ana de la Concepción, por lo que les solicitó la cesión de varios

20 A.D.M.S. leg. 1.091. 
tributos, entre ellos el del capitán y regidor de la ciudad Alonso Gómez, que valía 200 ducados, y el del sargento mayor y regidor Francisco de Isla de $400^{21}$. Sin la ayuda ducal, y con tan escaso caudal, no ha de extrañar que un empeño de esta envergadura prosiguiese lentamente en los años siguientes. El ayuntamiento colaboró en algo, y así el 6 de diciembre de 1667 concedió varias carretadas de piedra de El Puntal del Espíritu Santo ${ }^{22}$, pero poco se podía hacer con eso.

En cuanto a las fechas de construcción, Velázquez Gaztelu se equivoca rotundamente al afirmar que la iglesia se levantó entre 1677 y $1689^{23}$, puesto que hemos podido documentar que debió iniciarse nueve años antes, en 1668, ya que el 2 de mayo de ese año el provincial autorizó la compra de "una casa que esta contigua al dicho convento y es necesario para labrar la iglesia". Además se conservan diversas referencias documentales que nos confirman que la obra se encontraba en marcha en los años inmediatos. Por ejemplo, el 2 de septiembre de 1670 se autoriza por el Definitorio que los suelos del edificio bajo se levantasen al exterior 6 pies "más de lo que permite la ley", que eran 7, porque "el sitio a donde se fabrica está vecino a la marina, sujeto el suelo a diferentes avenidas de arena i aguas", y estima que para el interior bastaban sólo 3 más ${ }^{24}$. Otro dato contundente es que el 6 de mayo de 1673 se permite trasladar los huesos de Juana Bertia y su marido "a la iglesia nueva de nuestro convento de religiosos de Sanlúcar de Barrameda quando estuviera acabado", previa limosna de 100 ducados.

De las trazas originales, y de ciertas modificaciones que sobre ellas se llevaron a cabo, tenemos referencia por el permiso rubricado por el General de la orden, fray Diego de la Concepción, el 19 de enero de 1674, donde declara: "Por quanto estoy informado que en la planta hecha para la iglesia del convento de nuestros religiosos de Barrameda ay un defecto, que las ventanas de la capilla mayor, o presbiterio, están muy baxas, doy licencia al padre prior de dicho convento para que pueda hazer se levanten todo lo que pide el arte, y lo que se acostumbre en nuestros conventos a juicio de artífices peritos". Es decir, se mantiene la habitual fórmula en la arquitectura carmelitana de que uno de sus miembros con conocimientos en la materia sea el encargado de desplazarse al lugar que fuere preciso trazar una nueva obra, y con ello lograr uniformidad de criterio. Sin embargo, a veces, se producían defectos en el diseño por la mala acomodación al terreno o a las necesidades concretas de una comunidad. Por ello, en julio de ese año, el General envió un nuevo diseño para la fachada de los pies, que no debía contemplarse en la traza original, que sólo dispondría de planta. Se queja de estar algo destemplado, por lo que se excusa de que la carta la escribiese otra persona, "y remito con ella la planta para el frontispicio de la iglesia de Barrameda, aunque reparo en los dos torreones de encima, que parecen ser superfluos y fuera del estilo de la religión, y así para ellos no doy licencia, por lo menos de parte segunda”, o sea, para su ático o remate. Añade que pronto estaría en Sanlúcar y reconocería personalmente la obra y si eran oportunas las espadañas les daría el placet, lo que no sabemos si hizo, porque desde Granada, el 30 de octubre, autorizó al prior "para que pueda hacer un campanario en la iglesia de dicho convento, en la parte que mira a la ciudad, con condición que no exceda en él, al estilo común que la religión guarda", y también "hacer un corredor de sol al lado de la iglesia del sobredicho convento, encima de los confesonarios de los hermanos, sin exceder en nada a las medidas y costumbre”. Sabemos que por entonces la comunidad era escasa, ya que en 1671 sólo había siete sacerdotes y cuatro hermanos ${ }^{25}$.

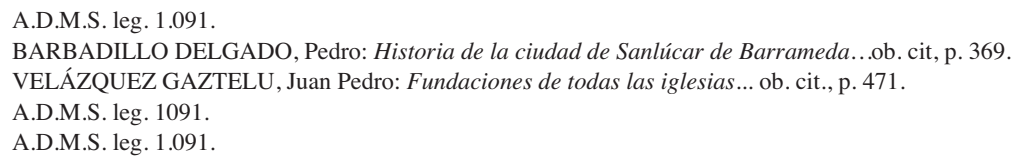


La construcción prosiguió en los años siguientes, y así, el 21 de marzo de 1676, se permitió que la capilla primera "de mano izquierda del cuerpo de iglesia" se agrandase dos varas "con un rincón que ay cerca de ella", rompiendo el arco del testero, y el 6 de febrero de 1680 se remitió al prior "la traza firmada para que se ejecute; no ha podido despacharse antes por aver estado ocupado el hermano trazador" 26 .

Según Velázquez Gaztelu, sin citar la fuente, la iglesia se levantó bajo la dirección de los maestros Francisco Pérez y Juan de Córdoba, "insignes en su arte, y aunque desnuda de todas las filigranas que suele aglomerar hoy la mal entendida arquitectura, no le falta por eso, ninguno de los requisitos que exige la justa proporción en sus medidas y tamaños" ${ }^{27}$. Aunque no se conserva la trazas original, ha llegado hasta nosotros una de 1731, (Lám.3) firmada por el hermano fray Bartolomé de San Pablo, en la que se califica de "Artista", y que fue aprobada por el General fray Antonio de la Asunción en Madrid el 4 de noviembre. En la planta se muestra

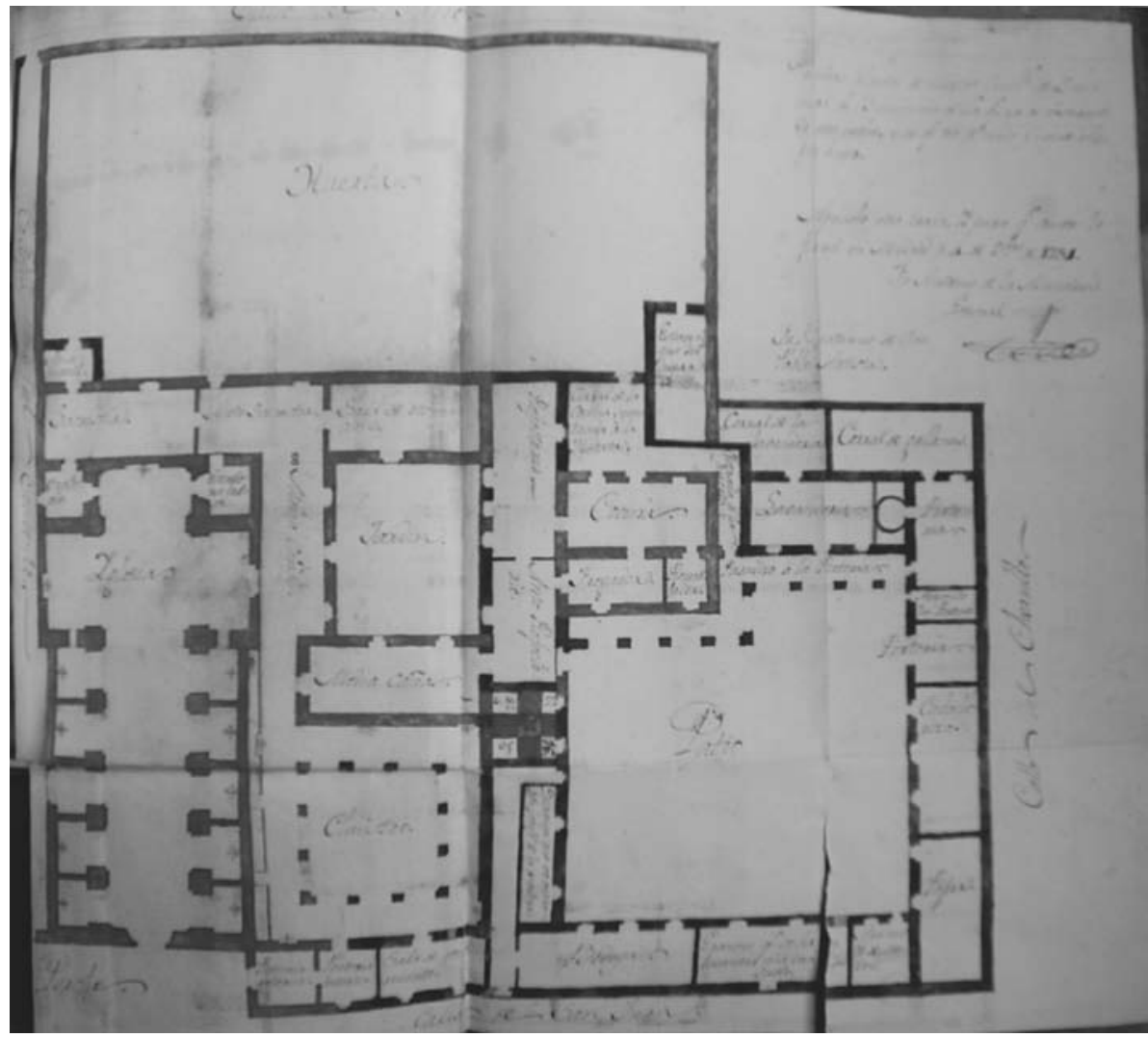

Lám. 3. Plano del convento del Carmen descalzo en la calle San Juan, actual parroquia del Carmen. 1731. A.D.M.S. leg. 1.009.

26 A.D.M.S. leg. 1.091.

27 VELÁZQUEZ GAZTELU, Juan Pedro: Fundaciones de todas las iglesias... ob. cit., pp. 471-472. 
lo construido para entonces, y se lee: "Primera planta de nuestro convento de Sanlúcar de Barrameda. Lo que va de encarnado está hecho, y lo que va de verde y negro está por hacer". El dibujo es de 48 x 42,5 cms., a la tinta marrón y almagra ${ }^{28}$. (Lám. 5) Otras obras menores se sucedieron en las primeras décadas del siglo XVIII, autorizadas al prior de turno para terminar una construcción inabarcable, como la del $1^{\circ}$ de junio de 1720 para una escalera; del $1^{\circ}$ de abril de 1727 "para que en la pared maestra de la iglesia, pueda abrir dos claraboyas a las dos últimas capillas de ella por causa de quitar las luces el nuevo cancel que se ha de poner" y "en la sala de recibimiento del dicho convento se pueda abrir en la pared maestra una ventana, por ser preciso cerrar otra de la misma sala"; o la del 4 de diciembre de 1729 para "comprar unas casas inmediatas al convento y para la continuación de su fábrica necesaria”. A pesar de ello, el 18 de diciembre de 1733, el prior envió una extensa carta al General donde le informaba como estaba "el convento atrasadísimo", aunque se había gastado "en obra, imágenes i divino culto" la friolera de 10.000 pesos, y solicitaba varias licencias que enmendasen lo que consideraba errores de la traza original, que obtuvo el 20 de enero del año siguiente.

La documentación nos desvela que el 29 de agosto de 1736 el maestro albañil y alarife Juan Rodríguez Portillo examinó la planta de 1731, cuando fue llamado para llevar a cabo la construcción "de un cuarto para oficio humilde", oponiéndose por faltar al diseño original y no ser el sitio el más adecuado. El 14 de enero de 1744 se autorizó el uso de 400 de los 500 ducados que se habían obtenido por los derechos de enterramiento privado en la capilla de San Juan de la Cruz, y por una memoria fundada, para "la fábrica del aguamanil y otras oficinas necesarias por la estrechez. que padece dicho convento", y finalmente el 24 de octubre de 1747 para comprar "una casa contigua a dicho convento, que se necesita para la continuación de su fábrica"29.

El templo, con la fachada de los pies hacia la calle San Juan, dispone de un amplio atrio con antepecho de ladrillo visto enrejado de factura moderna, donde abrían tres puertas, la central de acceso a la iglesia, y las laterales a la portería y al callejón privado, ésta desaparecida. De fábrica de ladrillo, su planta responde al austero modelo contrarreformista, y aunque a veces resulta forzado hablar de una arquitectura propia de las "órdenes", con unos planteamientos estructurales y decorativos conforme a lo específico de la regla, que a lo sumo matiza o enfatiza determinado aspecto de la funcionalidad litúrgica común, quizás se haya escrito con más fundamento sobre la existencia de una carmelitana. Y es que formada a lo largo de los siglos XVI y XVII, presenta unos rasgos que, si comunes a todas las órdenes mendicantes, en ésta se extreman, buscando plasmar aquella recomendación de Santa Teresa en su obra Camino de la perfección (II, 9 y 10), pues concluye que de nada valen grandes edificios ya que al final de los tiempos serán destruidos por el Juicio Divino. Una exigencia de austeridad que se vuelve a repetir en las llamadas Constituciones de Alcalá, de 1581, en las que intervino San Juan de la Cruz (cap. II, $1^{\text {a }}$ parte), que parecen afectar al diseño de sus templos, aunque las referencias normativas sean más tardías, como el Breve pontificio de 14 de marzo de 1786, que establece que "La anchura de nuestras iglesias oscilará entre siete u ocho metros, y conforme a esta medida se guardará la debida proporción para la largura y altura". Unas pequeñas proporciones que buscan esa ansiada humildad, pero no hay concreción tipológica ni decorativa. Posteriores y más completas son las Constituciones de la Congregación de San Elías, dadas en Roma en 1875, en las que además de prefijar las dimensiones prohíben revestir los muros de oro, mármol u otros materiales preciosos, pues se debía buscar el decoro ${ }^{30}$.

\footnotetext{
A.D.M.S. leg. 1.009 .

A.D.M.S. leg. 1.091

SEBASTIÁN, Santiago: Contrarreforma y Barroco. Lecturas iconográficas e iconológicas. Madrid: Alianza Forma, 1989, pp. 240-241.
} 
Esta iglesia sanluqueña reproduce en buena medida el modelo de la sevillana del Santo Ángel de la Guarda, de la misma orden y que puede ser su referente, trazada por Alonso de Vandelvira en $1603^{31}$. Presenta una sencilla planta de cajón de cruz latina de amplia nave única, con transepto de brazos cortos y capilla mayor en alto, sobre seis gradas de mármol, de escasa profundidad y testero plano. El alzado interior responde a esa búsqueda de austeridad, con los muros de la nave articulados por gruesos y sencillos pilares cuadrangulares, con arcos formeros de medio punto e imposta como capitel, sobre los que se dispone paramento liso, hábil para cuadros pictóricos. La verticalidad queda realzada por medio de leves pilastras adosadas a los pilares, sin capitel, salvo una caja, que se vinculan entre sí por una línea de imposta, y soportan arquitrabe, friso moldurado y una volada cornisa de variadas molduras rectilíneas de desarrollo creciente. Ese sentimiento se remarca con el juego de la cubierta, de bóveda tabicada de cañón con arcos fajones y lunetos perforados con un vano de medio punto, mera prolongación aérea y curva de las pilastras, que conducen animadamente la mirada del fiel hasta la cabecera. Ese espacio camino, de desarrollo longitudinal, se adapta a la finalidad docente de la orden, en que la predicación desde el púlpito era básica, pero por necesidades de mayor superficie se amplía lateralmente con dos tandas de cinco capillas, comunicadas entre sí y abiertas a la nave, originadas entre los pilares interiores y un muro perimetral, dispuestas para devociones y misas particulares, una de las cuales, actualmente cegada, en el muro del evangelio, abría como puerta al callejón del Carmen. En esa misma línea, la tercera de las capillas, fue adaptada como bautismal cuando el templo se transformó en parroquia. (Lám. 4)
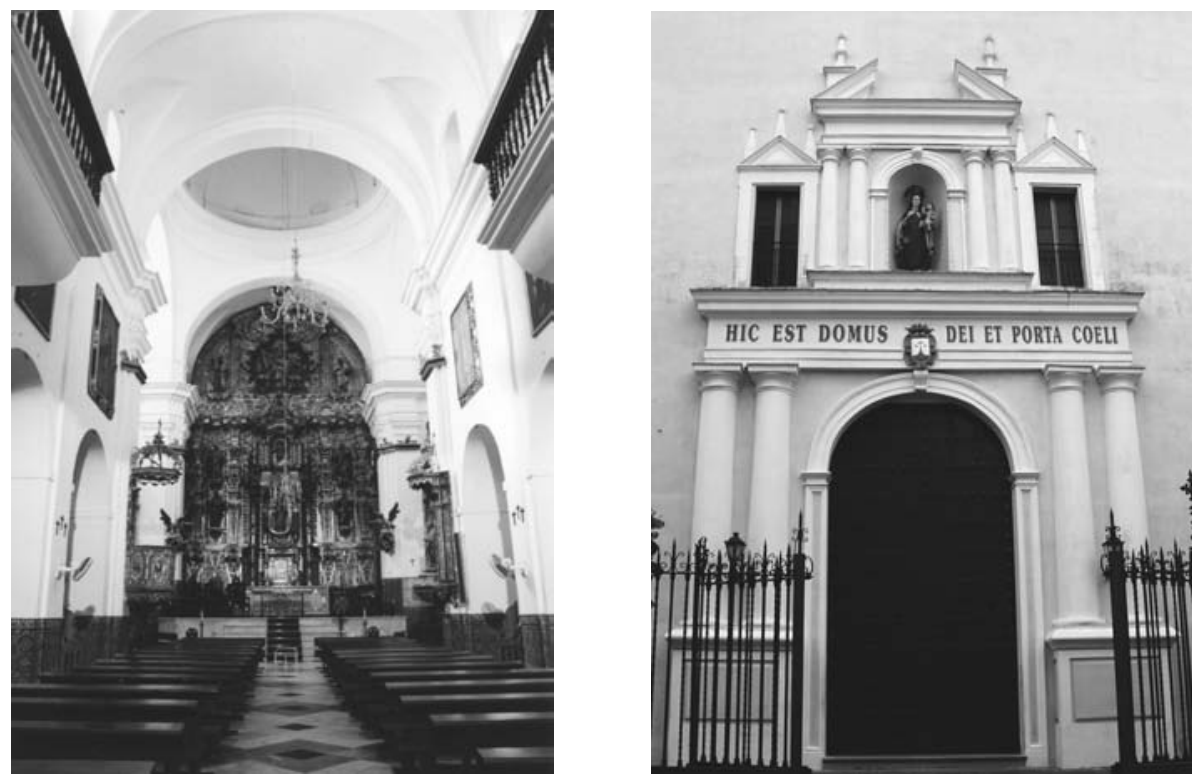

Láms. 4 y 5. Interior y fachada de los pies de la iglesia del Carmen descalzo, actual parroquia homónima

31 CRUZ ISIDORO, Fernando: Alonso de Vandelvira (1544-ca.1626/7). Tratadista y arquitecto andaluz. Sevilla: Universidad, 2001, pp. 129-145. 
El transepto se origina por la ausencia de capillas, adaptándose a la planta rectangular, cubriéndose igualmente con cañón, con testeros semicirculares donde abren vanos con vidrieras polícromas. El crucero lo forman cuatro pilares cruciformes sobre los que se adosan dos pilastras, de friso cajeado, cargando finalmente los arcos torales en los que se alza, sobre pechinas y un anillo moldurado, una media naranja gallonada por leves pilastras, con zócalo de óculos cegados. Al exterior, los abovedamientos quedan protegidos por una cubierta de madera tejada. En alto y a los pies se eleva el coro conventual, cargando sobre un tramo y un gran arco escarzado, adoptando una planta en forma de $U$ por la presencia volada en los extremos, sobre los muros de la nave, de dos salientes o balcones en forma de moldurón en talón o cima reversa. Sobre el ala de la epístola se yergue el órgano barroco. La trasera de la puerta de ingreso a la iglesia adopta igualmente una forma monumental, al constituirse por un gran dintel escoltado por pilastras pareadas toscanas y un interesante frontón curvo roto de remate mixtilíneo, que nos recuerda que la obra, por muy carmelitana que sea, se realiza en la época del decorativismo barroco.

La supuesta pureza y austeridad "evangélica" del interior, reforzada por el blancor enjalbegado de yeso, que resalta la abundante luz que entra por los sencillos ventanales del claristorio, y que propicia la reformadora Santa Teresa, se rompe por la exultante riqueza visual del brillante y aparatoso aspecto de ascuas doradas y polícromas del magnífico conjunto de máquinas retablísticas dieciochescas y neoclásicas, y por las suntuosas y engañosas portadas de madera policromada imitando jaspes que abren en los laterales de la capilla mayor, que debieron ser sufragadas, al igual que el retablo mayor, por el matrimonio formado por Pedro Esteban González de Ceballos Nieto y Jacinta Ruiz de Garibay Leonés Ladrón de Guevara, patronos del convento al adquirir en 1762 derecho de enterramiento en la bóveda funeraria de la capilla mayor, como se dejó constancia en una lápida de mármol con su escudo e inscripción, que actualmente se halla empotrada en el pasillo de la antigua portería.

En cuanto al exterior, el templo sólo presenta monumentalizada la fachada de los pies, pues el lateral derecho se adhería al conjunto conventual y el izquierdo queda semiabierto a un estrecho callejón privado. El hastial muestra un "limpio" y depurado aspecto seiscentista, centrado por una portada de cuerpo y ático, de potente arco triunfal de medio punto de rosca moldurada y jambas cajonadas entre parejas de semicolumnas toscanas alzadas sobre un pedestal común. (Lám. 5) Sobre su fuerte entablamento, y entre alargados ventanales de sencilla orejeta y frontón triangular coronado con pirámides con bolas, se desarrolla un pequeño edículo central que reproduce en miniatura el módulo del portal inferior, con hornacina para una Virgen del Carmen de desfigurada policromía, y remate en frontón roto con pequeños pináculos. Este ingreso se complementa con dos pequeñas portadas-retablo ciegas que la flanquean, a la manera de teatrales embocaduras planas que a ningún lado conducen, que son dinteladas y encierran un óculo circular de luces, de sencillo enmarque de orejeta y frontón triangular roto, que lanza en su vientre un pedestal muy alargado con pequeño basamento de piedra con inscripción, que sirve de soporte a una tarja de enrolladas volutas en el que se inscribe el escudo de la orden. Sobre la cornisa caneada de mútulos se levantan dos espadañas y un edículo central de enmarque de vano circular para aireación de la cubierta de madera. La que carga sobre el muro del evangelio es la de porte más arquitectónico, pues de las dos es la única que se ha terminado. De un cuerpo y ático decreciente, el inferior, que se yergue sobre antepecho cajeado, es de dos vanos de medio punto, de trasdós moldurado con clave e imposta corrida, que flanquean tres parejas de pilastras toscanas de fuste llagueado sobre ancones de tradición seiscentista. Sobre el entablamento con triglifos vuela la cornisa y un frontón recto roto, entre cuyas aletas coronadas con pirámides se origina el cuerpo menor, a la manera de un edículo, de un solo vano, de igual trasdós y clave muy marcada, con imposta corrida y 
entre pares de soportes similares, que sostienen un frontón curvo con análogo remate y cruz de hierro. En el centro se dispone un óculo abocinado de trasdós moldurado sencillo, inserto en un edículo rectangular apaisado, que se une a la espadaña anterior por un antepecho con imposta. Lo articulan dos pilastras toscanas y un frontón recto roto que lanza al viento sendas pirámides. Finalmente se encuentra, sobre el muro de la epístola, la segunda espadaña, de menor envergadura porque no llegó a terminarse, con sus parejas de ancones. Quedó en una estructura de un solo cuerpo y vano pequeño de medio punto de trasdós moldurado e imposta, con cornisa e interesante frontón de triple inflexión, de tradición manierista, con pedestal en la clave y veleta ${ }^{32}$.

En cuanto a la portada que abría a la portería, hoy a dependencias parroquiales, es de sencilla traza, de medio punto rebajado de trasdós moldurado, flanqueado por dos pilastras dóricas, sin basa, que sostienen entablamento con frontón curvo rebajado que se corona, en los extremos, con bolas sobre pedestales. Encima abre una ventana alargada. Parte del convento ha quedado integrada en modernas construcciones, como la fachada, abierta a la calle San Juan, que se origina desde ese portal. Otra antigua puerta de la iglesia, hoy cegada, abría desde una de las capillas al callejón del Carmen, de medio punto rebajado de trasdós moldurado y enmarque sencillo.

Con la ocupación francesa el convento sufrió su primera desamortización y su templo convertido en ayudantía de parroquia, regresando la comunidad tras la salida de las tropas invasoras, para sufrir de nuevo la exclaustración de 1821, que provocó que un año más tarde volviese a su función parroquial, hasta que la comunidad regresó por segunda vez en 1823 . Finalmente fue expulsada y la iglesia volvió a ser ayuda de parroquia desde 1836, y el inmueble utilizado como escuela gratuita, cuartel, escuela de Artes y Oficios, Academia de música, almacén municipal, etc ${ }^{33}$. Actualmente sirve como Centro de día de la Tercera Edad.

32 CALDERÓN QUIJANO, José Antonio: "Fortificaciones y Espadañas de Sanlúcar de Barrameda”. Boletín de Bellas Artes n XVI, (1988), pp.96-97. Del mismo autor: “Las espadañas de Sanlúcar”. Sanlúcar de Barrameda n 27, (1991), s./p.

33 GUILLAMAS Y GALIANO, Fernando: Historia de Sanlúcar de Barrameda ... ob. cit., p. 116. BARBADILLO DELGADO, Pedro: Historia de la ciudad de Sanlúcar de Barrameda ... ob. cit., p. 370. Véase también: PUERTA, P. Serafín, O.C.D.: Los carmelitas descalzos en Andalucía (1893-1979). Sevilla: Carmelitas descalzos, 1970. 